\title{
Study of hypovitaminosis D as a cause of chronic widespread pain in patients presenting to rheumatology clinic
}

Binit Vaidya, ${ }^{1 *}$ Shweta Nakarmi, ${ }^{1}$ Arvind Chaudhary, ${ }_{1}$ Poojan Batajoo, ${ }^{2}$ Nija Rajbhandari ${ }^{2}$

${ }^{1}$ Alka Hospital, Jawalakhel, Kathmandu, Nepal

${ }^{2}$ Nepal Medical College, Kathmandu, Nepal

\begin{abstract}
Accepted on
February 23, 2014

DOI Name

http://dx.doi.org/10.3126/jaim.v3i1.10694

Keywords

Chronic pain; fibromyalgia; vitamin D deficiency

\section{Citation}

Binit Vaidya, Shweta Nakarmi, Arvind Chaud-

hary, Poojan Batajoo, Nija Rajbhandari. Study of hypovitaminosis $D$ as a cause of chronic widespread pain in patients presenting to rheumatology clinic. Journal of Advances in Internal Medicine 2014;03(01):1-4.
\end{abstract}

\begin{abstract}
Background and aims: Hypovitaminosis D is common in south-east Asian countries. Deficient vitamin-D level is likely to be associated with chronic muscular pains. We do not have data from our country regarding the magnitude of this problem.
\end{abstract}

Methods: A prospective open labeled study at rheumatology opd from December 2009 to December 2012. Patients with chronic widespread pain and bone pains of $>3$ months duration were included in the study. Hypothyroidism, chronic renal failure and other rheumatological diagnosis except fibromyalgia were excluded. Visual analogue score (VAS) for pain and serum Vitamin-D levels were measured. Patients with low Vitamin-D were given oral Vitamin-D 60,000 IU for 6 months. Response to therapy was evaluated using improvement in VAS.

Results: Among 1680 patients, 66.2\% were females. Hypovitaminosis-D was seen in $1388(82.6 \%)$, of which $27.5 \%$ had severe deficiency with Vitamin D levels $<10 \mathrm{ng} / \mathrm{ml}$. Fibromyalgia overlap present in $25 \cdot 7 \%$. Mean initial VAS score was $8 \cdot 7,8 \cdot 2$ and $7 \cdot 4$ for patients in severe deficiency, mild deficiency and insufficiency group respectively. At 6 months follow-up, the VAS scores were $0,2 \cdot 1$ and 3.6 respectively. After 6 months of treatment, no improvement was seen in 196 patients (11.6\%) and all non-responders had fibromyalgia overlap. Vitamin-D level was checked again in non-responders and repeat vitamin-D levels were still low in 10 of them.

Conclusions: Hypovitaminosis-D can be a significant cause of Chronic widespread pain in the general population and seems to aggravate the pain of fibromyalgia. Improvement was rapid and better in severe cases.

\section{INTRODUCTION}

Chronic widespread pain (CWP) is highly prevalent worldwide. It reduces the quality of life and posts a huge economic burden. One study done in the Eastern part of Nepal estimated 50.3\% of the study population had pain of which $93.7 \%$ had chronic pain(>3months). The cost of pain related losses was estimated at (NRs) $1671 \cdot 89 /$ person/year as against the per capita GDP of NRs $98,640 \cdot 00$ (US\$ 1370). ${ }^{1}$

Of many types of chronic pain, nonspecific or chronic widespread pain is seen frequently in clinics. Precise diagnosis and treatment for such pain is difficult. There have been reviews and researches which have linked this type of pain with Hypovitaminosis $D^{2-8}$ whereas others have shown no association. ${ }^{9,10}$

Lately, understanding of the role of Vitamin D has shifted

\footnotetext{
* Corresponding author

Dr. Binit Vaidya

$M B B S, M D, F A C R$

Medicine Department, Alka Hospital, Jawalakhel,

Kathmandu, Nepal

Email: drbinitvaidya@yahoo.com
} 
from regulation of Calcium and bone health only. Its active metabolite has been shown to have antiproliferative and immunomodulatory effects that influence the development of several serious and chronic conditions, including cancers, ${ }^{11}$ cardiovascular diseases, ${ }^{12}$ and diabetes. ${ }^{13,14}$ Rickets and osteomalacia is now considered as the tip of the vitamin-D deficiency iceberg. ${ }^{15}$ With this new understanding, the severity grading for vitamin $D$ levels have been revisited but a consensus is yet to be formed. Studies have now shown that level $>30$ $\mathrm{ng} / \mathrm{ml}$ is required for maximal calcium absorption and keep parathyroid hormone levels at the lowest. Levels below 10ng/ $\mathrm{ml}$ have shown to induce osteomalacia and are called severe deficiency. ${ }^{16}$

We aim to study the prevalence and causal relationship of hypovitaminosis $D$ in our patients attending rheumatology clinic for CWP.

\section{METHODS}

This study is a prospective open labelled study conducted at Rheumatology Outpatient Department of Alka Hospital Pvt. Ltd in Kathmandu, Nepal from December 2009 to December 2012. Informed consent was taken from patients after explaining the nature of intervention and ethical clearance was taken from institutional board. Patient with chronic widespread muscle pains of $>3$ months duration were enrolled. Patients with uncontrolled hypothyroidism, other rheumatological diseases and chronic kidney disease were excluded from the study. Patients fulfilling the American College of Rheumatology (ACR) fibromyalgia (FMS) definition were not excluded from the study as pain of FMS can be chronic widespread and might be aggravated by underlying vitamin D insufficiency.

In the first part of the study, serum $25(\mathrm{OH})$ vitamin D levels were checked using enzyme immunoassay (EIA) method. Those with vitamin $D$ levels $<30 \mathrm{ng} / \mathrm{ml}$ were divided into 3 categories, $29-20 \mathrm{ng} / \mathrm{ml}$ as insufficiency; $<19-10 \mathrm{ng} / \mathrm{ml}$ as mild deficiency and $<10 \mathrm{ng} / \mathrm{ml}$ as severe insufficiency. The pain severity of patients was graded using Visual analogue score (VAS). All patients with Vitamin-D insufficiency or deficiency were treated with 60,000 IU of VitD3 (Cholecalciferol sachets) in milk once a week for 8 weeks and then once a month for 4 months (total 6 months). Each patient was evaluated using VAS at 3 months and 6 months. Improvement in VAS score by more than $20 \%$ was taken as significant improvement.

A small group of patients with chronic pain but no fibromyalgia were taken as controls ( $n=100)$. They were given 10 grams of glucose sachets of same size, to be taken in same way as cholecalciferol sachets. Their VAS score was also measured at 3 and 6 months following the same protocol.

In the second part of the study, serum $250 \mathrm{OH}$ vitamin D levels were re-evaluated in patients who did not show significant improvement in their pain scores. Those with vitamin $D$ levels still low were given parenteral vitamin D.

Other laboratory tests done were thyroid function tests, serum calcium, alkaline phosphatase and CRP levels. Serum parathyroid hormones were deliberately avoided due to cost reasons.

All statistical tests were done using SPSS 19. One way repeated measures ANOVA was used to test for the improvement is mean VAS score over time.

\section{RESULTS}

A total of 2000 patients were screened, out of which, 1680 patients were included in the study. Among them 1112 (66.2\%) were females. Hypovitaminosis $D(<30 \mathrm{ng} / \mathrm{dl})$ was present in $1388(82.6 \%)$ patients. Among those with inadequate levels, $20 \%$ (336) had values in insufficient range (20-30 ng/dl), $35 \cdot 12 \%$ (590) had mild deficiency (10-20ng/dl) and $27 \cdot 5 \%$ (462) had severe deficiency (<10ng/dl). [chart1]

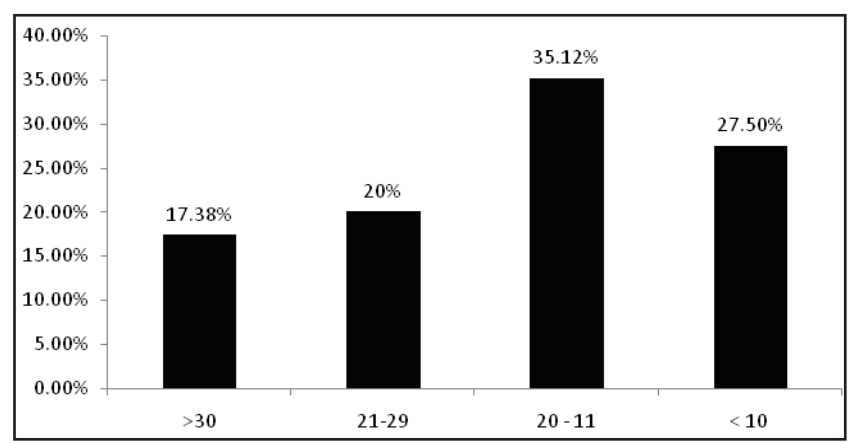

Chart 1. Distribution of vitamin D deficiency:

Among total patients, $432(25 \cdot 7 \%)$ had fibromyalgia overlap. Fibromyalgia was more common in females than in males $(p=$ 0.012). [chart2]

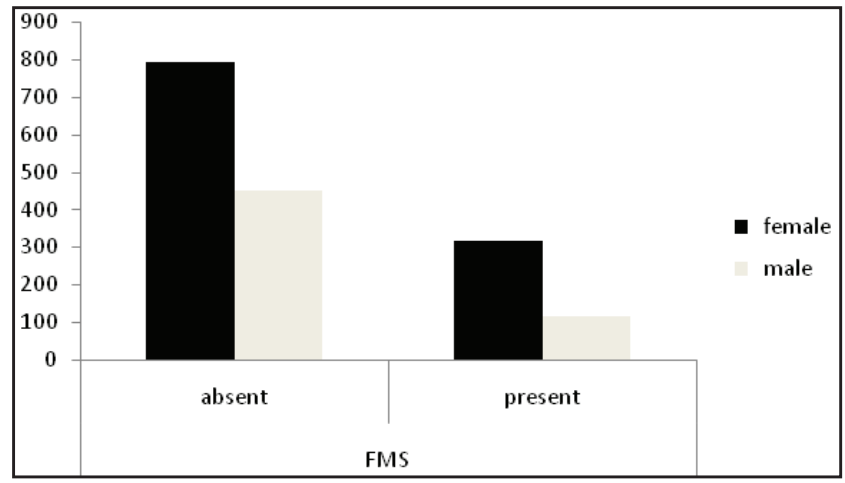

Chart 2. Gender distribution of fibromyalgia.

The mean initial VAS score was $8.7,8.2$ and 7.4 for patients in severe deficiency, mild deficiency and insufficiency groups respectively. At 6 months follow-up, the VAS scores were 0, 2.1 and 3.6 respectively for each group and the differences in each group were statistically significant. The control group showed slight but statistically insignificant improvement in initial 3 months which was not sustained over the period of 6 months. 
Table 1. Follow-up : Improvement in VAS score (Repeated measures ANOVA)

\begin{tabular}{lllll}
\hline \multicolumn{1}{c}{ Group } & Baseline & 3 months & 6 months & p-value \\
\hline Insufficiency & $7 \cdot 4$ & 3.5 & 3.6 & $<0.001$ \\
Mild Deficiency & 8.2 & 3 & 2.1 & $<0.0001$ \\
Severe Deficiency & 8.7 & 0 & 0 & $<0.0001$ \\
Control & 7.0 & 5.4 & 6.8 & 0.24 \\
\hline
\end{tabular}

Repeated measures ANOVA was used to assess the significance of improvement in VAS score over time. Mauchly's test indicated that the assumption of sphericity had been violated in all three groups, $\chi^{2}=89.3 ; 29.7 ; 74.9$ (severe, mild and insufficiency), $p=<0.001$, therefore degrees of freedom were corrected using Greenhouse-Geisser estimates of sphericity $(\epsilon<0.75)$. The results show that there was significant improvement in VAS score even after correction.

However, there was no improvement in 196 patients (11.6\%) and all non-responders had FMS overlap.

Repeat vitamin $D$ levels were still low in 10 patients who were treated with parenteral vitamin $D$. These patients had erratic follow-up as the dosing was once in 6 months and thus were not included in the study.

\section{DISCUSSION}

Chronic widespread pain is prevalent worldwide with reports of upto $26-50 \%$ of the screened population. ${ }^{17,18}$ Non-specific CWP not associated with any other known causative factor remains a difficult entity to treat. The prevalence of hypovitaminosis $D$ has been seen to be higher even in Indian subcontinent even with adequate sunlight exposure. ${ }^{19}$ In a cross sectional survey on Indo-Asian patients performed in UK, it was seen that vitamin $D$ levels were lower in patients attending the rheumatology clinic for musculoskeletal pain. ${ }^{20}$ We do not have population based study of prevalence from our country. However, in the screened population, the prevalence of $82.6 \%$ can be considered quite higher than expected. Many small and large studies from throughout the globe has shown association of muscle pains with vitamin D deficiency, ${ }^{2-8}$ whereas there are other studies refuting such an association. ${ }^{9-11}$ Our study not only showed high prevalence of hypovitaminosis $D$ but also showed significant improvement of pain scores after treatment with cholecalciferol supplement. Also, the lower the

\section{REFERENCES}

1) Bhattarai B, Pokhrel PK, Tripathi Met al. Chronic pain and cost: an epidemiological study in the communities of Sunsari district of Nepal. Nepal Med Coll J. 2007;9:6-11.

2) Nellen JF, Smulders YM, JosFrissen PH et al. Hypovitaminosis $D$ in immigrant women: slow to be diagnosed. BMJ.1996;312: 570-2.

http://dx.doi.org/10.1136/bmj.312.7030.570 initial vitamin D levels, the faster and more significant was the improvement in pain score.

Fibromyalgia is one cause of CWP where lab results remain negative. Thus, this study has included patients with FMS also. Moreover, FMS pain has shown to be increased by the presence of coexistent hypovitaminosis $D$ in studies from across the world and treatment with vitamin D supplements have shown to improve the pain scores in these patients significantly. ${ }^{21-25}$ But there were also studies showing no association of FMS with vitamin D levels. ${ }^{26-28}$ Most of these studies included small number of patients and none of the studies used a control group. In our study, FMS was diagnosed in $27 \cdot 5 \%$ of patients and most of them responded to treatment with vitamin D. Also, among vitamin D non responders, all patients had FMS overlap indicating a grey zone between these causative factors. It would also mean that those patients might require additional treatment for FMS. Additional large studies primarily aiming to study relationship between FMS and vitamin D are needed for definite answer to this question.

Patients with very low vitamin $D$ levels can thus be prognosticated to do well within 3 to 6 months of treatment and those with higher baseline levels or with classical FMS would benefit from combination of cholecalciferol supplement and any approved drug for FMS.

Several possible mechanisms may explain improvement in muscle pain with vitamin D. A rapid nongenomic influence of vitamin $D$ on the metabolism of muscle cells ${ }^{29}$ and mineralization of osteoid matrix seem to be most plausible mechanisms currently. ${ }^{30}$

\section{CONCLUSIONS}

Hypovitaminosis D is commonly found in our community and is a common causative factor of CWP. Fibromyalgia symptoms seem to be aggravated by co-existing hypovitaminosis D. Significant proportion of patients improve with correction of their vitamin D levels, however, those with coexisting fibromyalgia may need additional treatments.

\section{ACKNOWLEDGEMENT}

We would like to thank $\mathrm{Dr}$ Ashok Kumar, consultant rheumatologist at Fortis Hospital for guiding us during the course of study.

3) Erkal MZ, Wilde J, Bilgin Yet al. High prevalence of vitamin $\mathrm{D}$ deficiency, secondary hyperparathyroidism and generalized bone pain in Turkish immigrants in Germany: identification of risk factors. Osteoporos Int.2006;17:1133-40.

http://dx.doi.org/10.1007/s00198-006-0069-2

4) Reed SD, Laya MB, Melville J et al. Prevalence of vitamin $D$ insufficiency and clinical associations among veiled East African women in Washington State. J Womens 
Health (Larchmt).2007;16:206-13.

http://dx.doi.org/10.1089/jwh.2006.0089

5) Plotnikoff GA, Quigley JM. Prevalence of severe hypovitaminosis $D$ in patients with persistent, nonspecific musculoskeletal pain. Mayo Clin Proc. 2003;78:1463-70.

http://dx.doi.org/10.4065/78.12.1463

6) Armstrong DJ, Meenagh GK, Bickle I et al. Vitamin D deficiency is associated with anxiety and depression in fibromyalgia. ClinRheumatol.2007;26:551-4.

http://dx.doi.org/10.1007/s10067-006-0348-5

7) Mouyis M, Ostor AJ, Crisp AJ et al. Hypovitaminosis D among rheumatology outpatients in clinical practice. Rheumatology (Oxford). 2008;47:1267-8.

http://dx.doi.org/10.1093/rheumatology/ken203

8) Atherton K, Berry DJ, Parsons T et al. Vitamin D and chronic widespread pain in a white middle-aged British population: evidence from a cross-sectional population survey. Ann Rheum Dis.2009;68:817-22.

http://dx.doi.org/10.1136/ard.2008.090456

9) Block SR. Vitamin D deficiency is not associated with nonspecific musculoskeletal pain syndromes including fibromyalgia. Mayo Clin Proc.2004; 79:1585-6. http://dx.doi.org/10.4065/79.12.1585

10) Warner AE, Arnspiger $S A$. Diffuse musculoskeletal pain is not associated with low vitamin D levels or improved by treatment with vitamin D. J ClinRheumatol.2008;14:12-16. http://dx.doi.org/10.1097/RHU.0b013e31816356a9

11) Holick MF. Vitamin D: its role in cancer prevention and treatment. ProgBiophysMol Biol. 2006;92:49-59. http://dx.doi.org/10.1016/j.pbiomolbio.2006.02.014

12) Karakas M, Thorand B, Zierer A et al. Low levels of serum 25-hydroxyvitamin $D$ are associated with increased risk of myocardial infarction, especially in women: results from the MONICA/KORA Augsburg case-cohort study. J ClinEndocrinolMetab.2013;98:272-80.

http://dx.doi.org/10.1210/jc.2012-2368

13) Gysemans C, Bouillon R, Mathieu C. Vitamin Dand diabetes. EndocrinolMetabClin North Am. 2010;39:419-46.

http://dx.doi.org/10.1016/j.ecl.2010.02.013

14) Schöttker B, Haug U, Schomburg L et al. Strong associations of 25-hydroxyvitamin D concentrations with all-cause, cardiovascular, cancer, and respiratory disease mortality in a large cohort study. Am J ClinNutr. 2013;97:782-93.

http://dx.doi.org/10.3945/ajcn.112.047712

15) Szabó A. Skeletal and extra-skeletal consequences of vitamin D deficiency. OrvHetil. 2011;152:1312-9. http://dx.doi.org/10.1556/OH.2011.29186

16) Gómez A C, Naves-Díaz ML, Fernández MJ et al. Vitamin $D$ status and secondary hyperparathyroidism: The importance of 25-hydroxyvitamin D cut-off levels. Kidney International. 2003;63:S44-S48. http://dx.doi.org/10.1046/j.1523-1755.63.s85.11.x

17) van der Meer IM. Prevalence of vitamin $D$ deficiency among Turkish, Moroccan, Indian and sub-Sahara African populations in Europe and their countries of origin: an overview. Osteoporos Int.2011;22:1009-21. http://dx.doi.org/10.1007/s00198-010-1279-1

18) Mithal A, Wahl DA. Global vitamin $D$ status and determinants of hypovitaminosis D. Osteoporos Int. 2009;20:1807-20.

http://dx.doi.org/10.1007/s00198-009-0954-6

19) Harinarayan CV, Joshi SR. Vitamin D status in India--its implications and remedial measures. J Assoc Physicians India. 2009;57:40-8.

20) Serhan E, Newton $P$, Ali $H A$ et al. Prevalence of hypovitaminosis $D$ in Indo-Asian patients attending a rheumatology clinic. Bone. 1999;25:609-11. http://dx.doi.org/10.1016/S8756-3282(99)00209-4

21) Abokrysha NT. Vitamin D deficiency in women with fibromyalgia in Saudi Arabia. Pain Med. 2012;13:452-8. http://dx.doi.org/10.1111/j.1526-4637.2011.01304.x

22) Matthana $\mathrm{MH}$. The relation between vitamin $D$ deficiency and fibromyalgia syndrome in women. Saudi Med J. 2011;32:925-9.

23) Bhatty SA, Shaikh NA, Irfan M et al. Vitamin D deficiency in fibromyalgia. J Pak Med Assoc. 2010;60:949-51.

24) Heidari B, Shirvani JS, FirouzjahiA et al. Association between nonspecific skeletal pain and vitamin $D$ deficiency.Int J Rheum Dis. 2010;13:340-6. http://dx.doi.org/10.1111/j.1756-185X.2010.01561.x

25) McBeth J, Pye SR, O'Neill TW et al. Musculoskeletal pain is associated with very low levels of vitamin $D$ in men: results from the European Male Ageing Study. Ann Rheum Dis. 2010;69:1448-52.

http://dx.doi.org/10.1136/ard.2009.116053

26) Daniel D, Pirotta MV. Fibromyalgia--should we be testing and treating for vitamin D deficiency? AustFam Physician. 2011;40:712-6.

27) deRezende P C, Grillo LP, das Chagas Medeiros MM. Evaluation of 25-hydroxyvitamin $D$ serum levels in patients with fibromyalgia. J ClinRheumatol. 2010;16:365-9.

28) Tandeter $\mathrm{H}$, Grynbaum M, Zuili I et al. Serum $25-\mathrm{OH}$ vitamin $D$ levels in patients with fibromyalgia.Isr Med Assoc J. 2009;11:339-42.

29) Bischoff HA, Borchers $M$, Gudat F et al. In situ detection of 1,25-dihydroxyvitamin D3 receptor in human skeletal muscle tissue. Histochem J. 2001;33:19-24. http://dx.doi.org/10.1023/A:1017535728844

30) Priemel $M$, von Domarus $C$, Klatte TO et al. Bone mineralization defects and vitamin $D$ deficiency: histomorphometric analysis of iliac crest bone biopsies and circulating 25-hydroxyvitamin D in 675 patients. J Bone Miner Res. 2010;25:305-12.

http://dx.doi.org/10.1359/jbmr.090728 